\title{
DESENVOLVIMENTO E AVALIAÇÃO DE UM PULVERIZADOR HIDRÁULICO DE BARRAS RÍGIDAS HORIZONTAIS DE BAIXO CUSTO
}

\section{JORGE ALFREDO LUIZ FRANÇA ${ }^{1}$, WAGNER SANTOS GONÇALVES ${ }^{1}$, BRUNO PERES ROMEIRO ${ }^{1}$, CLEITON GREDSON SABIN BENETT ${ }^{1}$, ANDERSON RODRIGO DA SILVA ${ }^{1}$}

\footnotetext{
${ }^{1}$ Instituto Federal Goiano, Campus de Urutaí, Urutaí/GO, Brasil, jorge.10.franca@gmail.com, wwagnerr@gmail.com, brunopromeiro@hotmail.com, cbenett@hotmail.com, anderson.silva@ifgoiano.edu.br
}

RESUMO: Encontram-se no mercado diversos modelos de pulverizador costal manual que nem sempre atendem a necessidade do pequeno produtor, pois o uso destes equipamentos demandam excessivo tempo e mão-de-obra. Objetivou-se nesse trabalho desenvolver um pulverizador hidráulico de barras rígidas horizontais de baixo custo e avaliar a uniformidade de vazão dos bicos de pulverização ao longo das barras. $\mathrm{O}$ trabalho foi realizado no Instituto Federal Goiano - Campus Urutaí. O experimento foi realizado em blocos casualizados em esquema fatorial $2 \times 12$ (duas rotações na tomada de potência do trator e 12 bicos de pulverização). Foram utilizadas as rotações de 540 e 750 RPM na tomada de potência do trator, as quais proporcionaram pressões de serviço de 118 e $211 \mathrm{kPa}$, respectivamente. Foram coletadas as vazões $\left(\mathrm{L} \min ^{-1}\right)$ de todos os bicos de pulverização, por meio de proveta graduada, com três repetições. Os dados foram submetidos ao critério de Scott-Knott no software de análises estatísticas $R$. As rotações influenciaram nas vazões dos bicos de pulverização. Os coeficientes de variação das vazões mantiveram-se abaixo dos limites de uniformidade citados pela literatura.

PALAVRAS-CHAVE: agricultura familiar, máquinas agrícolas, vazão, uniformidade.

\section{DEVELOPMENT AND EVALUATION OF A LOW COST HYDRAULIC SPRAYER WITH RIGID HORIZONTAL BARS}

\begin{abstract}
They are on the market several knapsack sprayer models, which do not always meet the need of small farmers, because the use of these devices require excessive time and work force. This work aimed to develop a low cost hydraulic sprayer with rigid horizontal bars and evaluate its nozzles flow uniformity along the bars. The study was carried out at the Instituto Federal Goiano, in Urutaí-GO. The experimental design was a $2 \times 12$ factorial in complete randomized blocks, with four replications. Treatments consisted of two rotations in the tractor power take-off (PTO) and 12 spray nozzles). Rotations of 540 and $750 \mathrm{rpm}$ in the power take-off were used, these rotations result in operating pressures of 118 and $211 \mathrm{kPa}$, respectively. Flow rates were collected (min-1 L) of all spray nozzles using a graduated cylinder, with three replications. The data were submitted to the Scott-Knott test using the software R. The rotations influenced the flow rates of spray nozzles. The coefficients of variation of flow rate remained below the uniformity limits cited in the literature.
\end{abstract}

KEYWORDS: familiar agriculture, agricultural machines, rate, uniformity. 


\section{INTRODUÇÃO}

A utilização de defensivos agrícolas constitui uma prática comum no controle de pragas e doenças na maioria das culturas, representando parte significativa nos custos de produção. Portanto, são de interesse para os agricultores, a máxima efetividade e custos mínimos na aplicação destes produtos.

Um dos grandes desafios para a comunidade envolvida no processo de produção de alimentos é produzir mais, com menor custo e menor utilização de produtos fitossanitários, sem agredir ao homem e ao ambiente (BAUER et al., 2009).

Toda e qualquer forma de aplicação de defensivos agrícolas representa risco ao ambiente, no entanto, estes riscos podem ser minimizados por meio do uso de tecnologia e conhecimento adequados, garantindo produção sustentável de alimentos. Além disso, a preocupação com a preservação do ambiente e produção de alimentos livre de contaminação necessitam de máquinas mais eficientes (BAESSO et al., 2009) que propiciem menos desperdício dos produtos aplicados.

Tradicionalmente, há, na sociedade, o pensamento de que os defensivos agrícolas são prejudiciais ao homem, devido ás notícias de contaminação de animais e seres humanos (CUNHA et al., 2003), no entanto, se aplicados na dosagem adequada e racional, podem reduzir as perdas provenientes de pragas e a sua contaminação pode ser mínima (CUNHA; RUAS, 2006).

Os pulverizadores hidráulicos de barra são as máquinas mais utilizadas na aplicação dos defensivos agrícolas com a finalidade de subdividir a calda uniforme ao longo da barra, distribuindo-as na superfície a ser tratada, e a escolha e formas de uso desses equipamentos são fundamentais para que se obtenha a ação eficaz dos defensivos agrícolas (DORNELLES et al., 2011; SILVEIRA, 2001).

Neste contexto estão inseridos os pulverizadores hidráulicos manuais de bombeamento prévio ou contínuo, os quais são indicados para culturas em pequenas áreas (SILVEIRA, 1989). Segundo Lopes et al. (2011), esses equipamentos apesar do baixo custo, possuem desvantagens como serem carregados e acionados manualmente, ficando sujeitos a variação de pressão de trabalho e a redução da capacidade operacional. Esse problema pode ser minimizado quando o acionamento e o transporte são mecanizados.

Encontram-se no mercado diversos modelos de pulverizador costal manual, que nem sempre atendem a necessidade do pequeno produtor, pois demandam excessivo tempo e mãode-obra, se comparados aos pulverizadores de barras. A eficiência do trabalho de pulverização manual pode ser afetada também pelas condições de saúde do operador, pois a atividade demanda de considerável gasto energético do operador (SASAKI et al., 2014).

Existem também pulverizadores pneumáticos e hidropneumáticos que conseguem aplicar a calda a distâncias elevadas, no entanto causam desconforto auditivo ao operador (CUNHA; TEODORO, 2006). Mion et al. (2009) informam que a exposição ao ruído é a principal causa das perdas auditivas relacionadas ao trabalho.

De acordo com Sasaki et al. (2014), os níveis produzidos por pulverizadores portáteis motorizados são superiores ao recomendado pela norma NR-15, que recomenda valores inferiores a $85 \mathrm{~dB}$ para uma jornada de trabalho de $8 \mathrm{~h}$ e sem o uso de protetor auricular. Ainda de acordo com essa norma, sem o uso de protetor auricular o equipamento pneumático que apresentar nível de ruído próximos de $100 \mathrm{~dB}$, a máxima exposição diária a ele é de apenas $1 \mathrm{~h}$; para o termonebulizador, com valores próximos de $95 \mathrm{~dB}$, essa permanência é de $2 \mathrm{~h}$. 
Visando o aumento da capacidade operacional e melhoria nas condições de trabalho, os pulverizadores costais manuais são normalmente substituídos por pulverizadores em que o transporte e acionamento são feitos por meio de tratores e/ou outro meio mecânico. $\mathrm{O}$ transporte pode ser feito pelo sistema de levante hidráulico de três pontos e o acionamento do sistema de pulverização pela tomada de potência do trator.

Assim, objetivou-se nesse trabalho avaliar a uniformidade de vazão dos bicos de pulverização ao longo das barras de um pulverizador hidráulico de barras rígidas horizontais, para tratores com baixa demanda de potência, em duas rotações na tomada de potência do trator.

\section{MATERIAL E MÉTODOS}

O trabalho foi realizado no Instituto Federal Goiano - Câmpus Urutaí-GO, com altitude média de $821 \mathrm{~m}$, latitude $17^{\circ} 27^{\prime} 52^{\prime \prime}$ Sul e longitude $48^{\circ} 12^{\prime} 13^{\prime \prime}$ Oeste. Segundo classificação Köppen, o clima é Cwa, caracterizado como úmido tropical com inverno seco e verão chuvoso.

Foi utilizado um pulverizador desenvolvido no Instituto Federal Goiano - Campus Urutaí, o qual consta de um chassi metálico retangular, dois tanques de pulverizadores costais com capacidade para $20 \mathrm{~L}$ cada, caixa de redução, conjunto de engrenagens e sistema de manivela biela para acionamento do mecanismo de pressurização dos pulverizadores (Figura 1).

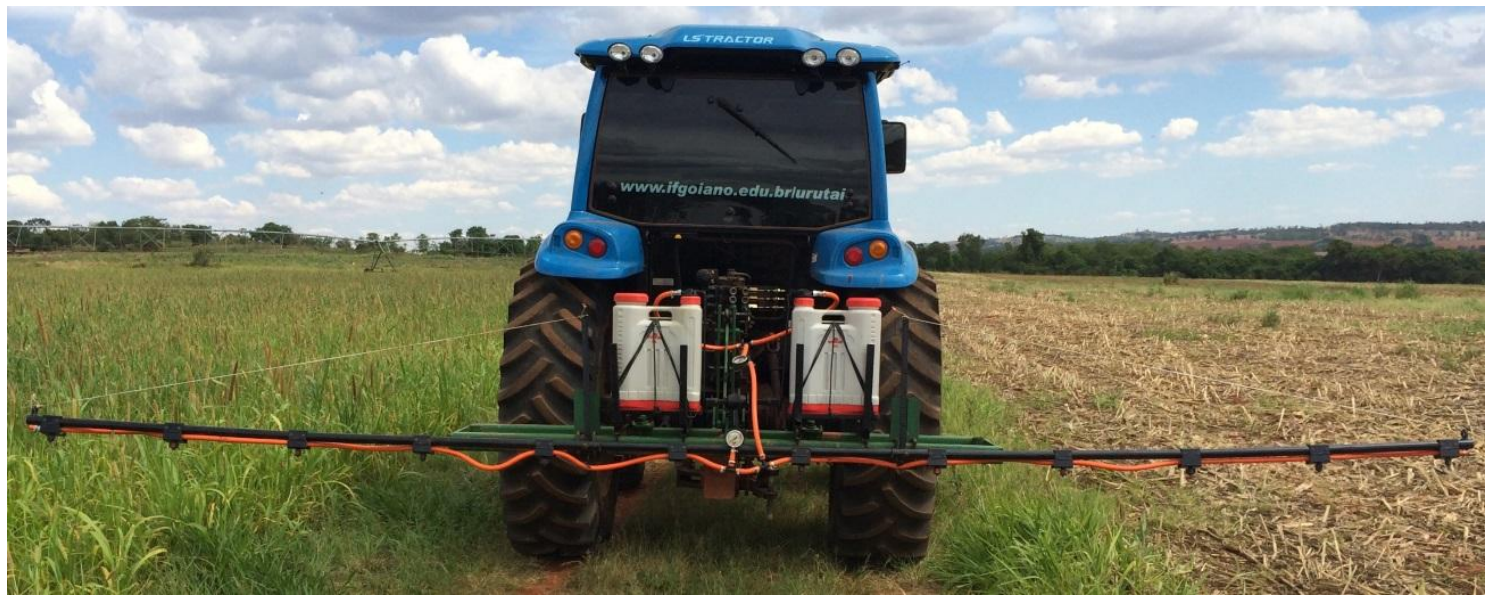

Figura 1. Pulverizador utilizado no experimento. Foto: J.A.L. França (2014)

Foram colocados dois tanques de pulverizadores costais de $20 \mathrm{~L}$ cada, com mecanismo de fixação que permite a retirada dos tanques para limpeza e reparos no cilindro de pressão. $\mathrm{O}$ mecanismo de suporte do reservatório de líquido foi construído em metal de modo a ser leve e prático, para que a manutenção da máquina seja possível de ser efetuada por apenas um operador. Como a máquina é destinada para uso em pequenas áreas, não foi necessário o uso de tanques de reservatório de líquido de grandes capacidades.

O comprimento total das barras de pulverização foi de seis metros e foram divididas em três secções, de modo que a secção central ficou fixa ao chassi e as secções laterais foram colocadas na posição vertical nos momentos de transporte e quando a máquina não era utilizada. As barras de pulverização possuíam perfil cilíndrico com mecanismo de suporte dos bicos de pulverização a cada $0,5 \mathrm{~m}$. As barras foram feitas de metal leve, minimizando a necessidade de sistema de amortecimento sem comprometer a estabilidade e causar danos às barras em terrenos irregulares. 
O sistema de bombeamento da calda foi feito a partir da potência disponível na tomada de potência do trator. A tomada de potência acionava uma caixa de redução acoplada ao chassi, que acionava um eixo com uma corrente, a qual acionava as engrenagens acopladas a um eixo que possuía sistema de manivela biela em cada uma das duas extremidades. Este sistema manivela biela transformava o movimento circular fornecido pela tomada de potência do trator em movimento do tipo alternado para acionamento dos tanques de pulverizadores costais. Os tanques de pulverização foram acionados por movimentos alternados do braço do operador, e com esta adaptação do sistema de acionamento dos tanques por meio do sistema manivela biela foi possível simular o movimento do tipo alternado para realizar o acionamento dos tanques de pulverização.

Foram utilizadas mangueiras de pulverização de meia polegada de diâmetro, um manômetro analógico com glicerina - instalado entre os tanques dos pulverizadores e os bicos de pulverização - para medição da pressão, pontas de pulverização tipo "leque" da marca Magno Jet, série TP cor azul, número 03, com ângulo de $110^{\circ}$, construídas em poliacetal, filtro de malha 50 e com vazão de $1 \mathrm{~L} \mathrm{~min}^{-1}$ (com pressão de $207 \mathrm{kPa}$ ) a $1,43 \mathrm{~L} \mathrm{~min}^{-1}$ (com pressão de $414 \mathrm{kPa}$ ) (MAGNO JET, 2014). Para transporte e acionamento dos pulverizadores foi utilizado um trator marca LS Tractor, modelo Plus de $88 \mathrm{cv}$. Durante o experimento a temperatura ambiente foi de $27^{\circ} \mathrm{C}$, a velocidade do vento de $7 \mathrm{~km} \mathrm{~h}^{-1}$ e a umidade relativa do ar de $35 \%$.

Para a avaliação da uniformidade da vazão ao longo da barra de pulverização foi realizado um experimento em delineamento de blocos casualizados, em esquema fatorial $2 \mathrm{x}$ 12, sendo duas rotações na tomada de potência do trator (540 e 750 RPM ) e 12 bicos de pulverização, com três repetições. As pressões de serviço foram de 118 e $211 \mathrm{KPa}$, respectivamente. Foram coletadas as vazões $\left(\mathrm{L} \mathrm{min}^{-1}\right)$ de todos os bicos de pulverização, por meio de proveta graduada. Os dados foram submetidos à análise de variância e as médias foram agrupadas de acordo com o critério de Scott-Knott ao nível de 5\% de probabilidade. As análises estatísticas foram realizadas no software R versão 3.0.3 (R CORE TEAM, 2014).

\section{RESULTADOS E DISCUSSÃO}

O pulverizador apresentou resistência mecânica satisfatória durante a realização do experimento. O sistema de manivela biela proporcionou o acionamento dos tanques dos pulverizadores de forma eficiente.

Na Tabela 1 observam-se os resultados obtidos para as vazões $\left(\mathrm{L} \mathrm{min}^{-1}\right)$ nos bicos de pulverização nas rotações de 540 e 750 RPM.

Volpe et al. (2012) sugeriram que, para experimentos desenvolvidos em condições de laboratório, os coeficientes de variação aceitáveis devem ser até $10 \%$, visto que, em aplicações realizadas em campo, o valor do coeficiente de variação tende a aumentar, devido as condições climáticas inerentes por ocasião da aplicação e/ou movimentos desordenados da barra de pulverização ocasionados pelo deslocamento do trator sobre o solo.

De acordo com a Tabela 1, observa-se que houve diferença significativa para as vazões $\left(\mathrm{L} \min ^{-1}\right)$ entre os bicos de pulverização nas rotações de 540 e $750 \mathrm{RPM}$ ao longo da barra de pulverização, todavia observou-se coeficiente de variação de 3,64\% e 5,69\%, respectivamente, valor que está de acordo com as recomendações de Volpe et al. (2012).

Analisando separadamente cada bico de pulverização entre as rotações na tomada de potência, observou-se diferença significativa para a vazão $\left(\mathrm{L} \mathrm{min}^{-1}\right)$. Entretanto este resultado já era esperado, visto que com o aumento da rotação da tomada de potência do trator de 540 
para 750 RPM, observou-se um acréscimo de 78,8\% da pressão, consequentemente verificouse o aumento da vazão dos bicos de pulverização. Viana et al. (2010); Fernandes et al. (2007), e Ferreira et al. (2009), trabalhando com pulverizadores, encontraram resultados semelhantes aos obtidos durante este experimento em relação à variação da vazão em função da rotação da tomada de potência do trator.

Tabela 1. Vazões $\left(\mathrm{L} \mathrm{min}^{-1}\right)$ nos bicos de pulverização nas rotações de 540 e 750 RPM. UrutaíGO, 2014.

\begin{tabular}{|c|c|c|}
\hline Bicos & 540 RPM & 750 RPM \\
\hline 1 & $0,82 \mathrm{bA}^{*}$ & $1,08 \mathrm{~dB}$ \\
\hline 2 & $0,83 \mathrm{bA}$ & $1,08 \mathrm{~dB}$ \\
\hline 3 & $0,84 \mathrm{bA}$ & $1,11 \mathrm{cB}$ \\
\hline 4 & $0,84 \mathrm{bA}$ & $1,12 \mathrm{cB}$ \\
\hline 5 & $0,83 \mathrm{bA}$ & $0,96 \mathrm{eB}$ \\
\hline 6 & $0,82 \mathrm{bA}$ & $1,05 \mathrm{~dB}$ \\
\hline 7 & $0,88 \mathrm{aA}$ & $1,15 \mathrm{bB}$ \\
\hline 8 & $0,86 \mathrm{aA}$ & $1,12 \mathrm{cB}$ \\
\hline 9 & $0,90 \mathrm{aA}$ & $1,19 \mathrm{aB}$ \\
\hline 10 & $0,82 \mathrm{bA}$ & $1,06 \mathrm{~dB}$ \\
\hline 11 & $0,83 \mathrm{bA}$ & $1,09 \mathrm{~dB}$ \\
\hline 12 & $0,78 \mathrm{bA}$ & $1,04 \mathrm{~dB}$ \\
\hline
\end{tabular}

*Médias seguidas pelas mesmas letras minúsculas nas colunas e maiúsculas nas linhas, para cada variável, são estatisticamente iguais pelo teste de Scott-Knott ao nível de 5\% de probabilidade.

De acordo com a Figura 2, observa-se que as rotações na tomada de potência do trator influenciaram nas vazões $\left(\mathrm{L} \min ^{-1}\right)$ dos bicos de pulverização. Todavia este resultado era esperado, visto que as rotações de 540 e 750 RPM produziram pressões de 118 e $211 \mathrm{kPa}$, respectivamente, as quais proporcionaram diferentes vazões $\left(\mathrm{L} \min ^{-1}\right)$ nos bicos de pulverização.

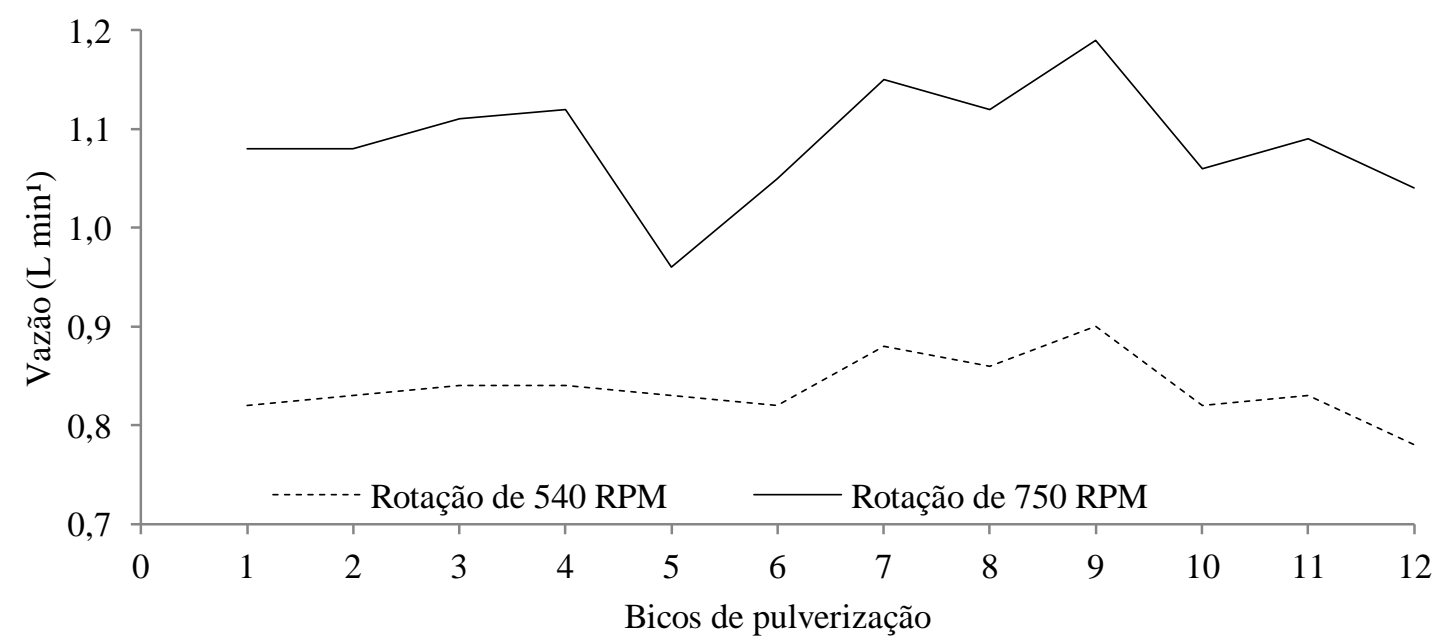

Figura 2. Perfil de distribuição da vazão $\left(\mathrm{L} \mathrm{min}^{-1}\right)$ ao longo da barra de pulverização. UrutaíGO, 2014. 


\section{CONCLUSÕES}

Com o aumento da rotação da TDP do trator de 540 para 750 RPM, observou-se um acréscimo de 78,8\% da pressão, consequentemente verificou-se o aumento da vazão dos bicos de pulverização.

Os coeficientes de variação das vazões $\left(\mathrm{L} \mathrm{min}^{-1}\right)$ para as rotações de 540 e 750 RPM mantiveram-se abaixo dos limites de uniformidade citados pela literatura.

\section{REFERÊNCIAS BIBLIOGRÁFICAS}

BAESSO, M. M.; GOULART JUNIOR, R.; TEIXEIRA, M. M.; AUGUSTO, F.; RODRIGUES JUNIOR, F. A.; RUAS, R. A. A. Avaliação da uniformidade de distribuição volumétrica de bicos hidráulicos em pulverizador com assistência de ar. Engenharia na agricultura, Viçosa-MG, v. 17, n. 2, p. 120-127, 2009. Disponível em: http://www.seer.ufv.br/seer/index.php/reveng/article/viewFile/119/54. Acesso em: 12 de Nov. de 2014.

BAUER, F. C.; PEREIRA, F. A. R.; SCHEEREN, B. R.; BRAGA, L. W. Diagnóstico das condições, tempo de uso e manutenção de pulverizadores no Estado de Mato Grosso do Sul. Engenharia Agrícola, Jaboticabal-SP v. 29, n. 3, p. 501-507, 2009. Disponível em: http://www.scielo.br/pdf/eagri/v29n3/a17v29n3. Acesso em: 25 de Out. de 2014.

CUNHA, J. P. A. R.; RUAS, R. A. A. Uniformidade de distribuição volumétrica de pontas de pulverização de jato plano duplo com indução de ar. Pesquisa Agropecuária Tropical, Goiânia-GO, v. 36, n. 1, p. 61-66, 2006. Disponível em: http://www.revistas.ufg.br/index.php/pat/article/viewArticle/2173. Acesso em: 11 de Nov. de 2014.

CUNHA, J. P. A.; TEIXEIRA, M. M.; COURY, J. R.; FERREIRA, L. R. Avaliação de estratégias para redução da deriva de agrotóxicos em pulverizações hidráulicas. Revista Planta Daninha, Viçosa-MG, v. 21, n. 2, p. 325-332, 2003. Disponível em: http://www.scielo.br/scielo.php?script=sci arttext\&pid=S0100-83582003000200019. Acesso em: 10 de Out. de 2014.

CUNHA, J. P. A. R.; TEODORO, R. E. F. Avaliação do nível de ruído em derriçadores mecânicos e pulverizadores motorizados portáteis utilizados em lavouras de café. Bioscience Journal, Uberlândia-MG v. 22, n. 3, p. 71-77, 2006. Disponível em: http://www.seer.ufu.br/index.php/biosciencejournal/article/view/6363/4112. Acesso em: $10 \mathrm{de}$ Nov. de 2014.

DORNELLES, M. E.; SCHLOSSER, J. F.; BOLLER, W.; RUSSINI, A.; CASALI, A. L. Inspeção técnica de tratores e pulverizadores utilizados em pulverização agrícola. Revista Engenharia na Agricultura, Viçosa-MG v. 19, n. 1, p. 36-43, 2011. Disponível em: http://www.seer.ufv.br/seer/index.php/reveng/article/viewFile/222/149. Acesso em: 15 de Out. de 2014.

FERNANDES, A.P.; PARREIRA, R. S.; FERREIRA, M. C.; ROMANI, G. N. Caracterização do perfil de deposição e do diâmetro de gotas e otimização do espaçamento entre bicos na barra de pulverização. Engenharia Agrícola, Jaboticabal-SP, v.27, n.3, p. 728-733, 2007. Disponível em: $\quad$ http://www.scielo.br/scielo.php?pid=S010069162007000400016\&script=sci_arttext. Acesso em: 31 de Out. de 2014.

FERREIRA, M. C.; OLIVEIRA, J. R. G.; PIETRO, I. R. P. S. D. Distribuição da calda herbicida por pontas de pulverização agrícola utilizadas em áreas de reflorestamento com 
eucalipto. Engenharia Agrícola, Jaboticabal-SP, v. 29, n. 2, p. 267-276, 2009. Disponível em: http://www.scielo.br/pdf/eagri/v29n2/10.pdf. Acesso em: 30 de Out. de 2014.

LOPES, E. S.; OLIVEIRA, F. M.; RODRIGUES, C. K. Determinação da carga física de trabalho na atividade de aplicação manual de herbicida. Ambiência Guarapuava, Guarapuava-PR, v. 7 , n. 2, p. 329-337, 2011. Disponível em: http://200.201.10.18/index.php/ambiencia/article/view/1055/1269. Acesso em: 10 de Nov. de 2014.

MAGNO JET, 2014. Disponível em: http://www.magnojet.com.br/magnojet/pt/produtos.php?Catalogo=detalhar_produto\&idProdu to=141\&nomeProd=bico_leque_serie_tp\&TipoMidiaProduto=Imagem. Acesso em: $10 \mathrm{de}$ Dez. de 2014.

MION, R. L.; VILIOTTI, C. A.; DANTAS, M. J. F.; SOUZA NASCIMENTO, E. M. Avaliação dos níveis de ruído de um conjunto mecanizado trator e semeadora adubadora pneumática. Revista Engenharia na Agricultura, Viçosa-MG, v. 17, n. 2, p. 87-92, 2009. Disponível em: http://www.bibliotekevirtual.org/revistas/REVENG/v17n02/v17n02a01.pdf. Acesso em: 11 de Nov. de 2014.

R CORE TEAM (2014). R: A language and environment for statistical computing. R Foundation for Statistical Computing, Vienna, Austria. Disponível em: http://www.Rproject.org/. Acesso em: 06 de Mar. de 2014.

SASAKI, R. S.; FURTADO JÚNIOR, M. R.; LEITE, E. da S.; SOUZA, A. P.; TEIXEIRA, M. .M.; FERNANDES, H. C. Avaliação ergonômica de pulverizadores costais utilizados no setor florestal, Revista Árvore, Viçosa-MG, V. 38, n. 2, p. 331-337, 2014. Disponível em: http://www.scielo.br/pdf/rarv/v38n2/13.pdf. Acesso em: 28 de Out. de 2014.

SILVEIRA, G. M. As máquinas para plantar. Rio de Janeiro-RJ: Globo, 1989, 257 p.

SILVEIRA, G. M. Máquinas para Plantio e Condução das Culturas. v. 3, Viçosa-MG: Aprenda Fácil Editora, 2001, 336 p.

VIANA, R. G.; FERREIRA, L. R.; FERREIRA. M. C.; TEIXEIRA, M. M.; ROSSEL, J. R.; SANTOS, L. D. T.; MACHADO, A. F. L. Distribuição volumétrica e espectro de gotas de pontas de pulverização de baixa deriva. Planta Daninha, Viçosa-MG, v. 28, n. 2, p. 439-446, 2010. Disponível em: http://www.scielo.br/pdf/pd/v28n2/a24v28n2.pdf. Acesso em: 01 de Nov. de 2014.

VOLPE, H. X. L.; DUARTE, R. T.; SILVA, A. G.; BALDAN JÚNIOR, E.; LEITE, G. J.; FERREIRA, M. C. Distribuição volumétrica de calda contendo Metarhizium anisopliae, Ciência Rural, Santa Maris-RS, v. 42, n. 11, p. 1909-1915, 2012. Disponível em: http://www.scielo.br/scielo.php?pid=S0103-84782012001100001\&script=sci_arttext\&tlng=es Acesso em: 01 de Nov. 